\title{
Equivalent design pressure for ship plates subjected to moving slamming impact loads
}

Zhu, Ling; Duan, Lele; Chen, Mingsheng; Yu, T.X.; Pedersen, Preben Terndrup

Published in:

Marine Structures

Link to article, DOI:

10.1016/j.marstruc.2020.102741

Publication date:

2020

Document Version

Peer reviewed version

Link back to DTU Orbit

Citation $(A P A)$ :

Zhu, L., Duan, L., Chen, M., Yu, T. X., \& Pedersen, P. T. (2020). Equivalent design pressure for ship plates subjected to moving slamming impact loads. Marine Structures, 71, [102741].

https://doi.org/10.1016/j.marstruc.2020.102741

\section{General rights}

Copyright and moral rights for the publications made accessible in the public portal are retained by the authors and/or other copyright owners and it is a condition of accessing publications that users recognise and abide by the legal requirements associated with these rights.

- Users may download and print one copy of any publication from the public portal for the purpose of private study or research.

- You may not further distribute the material or use it for any profit-making activity or commercial gain

- You may freely distribute the URL identifying the publication in the public portal

If you believe that this document breaches copyright please contact us providing details, and we will remove access to the work immediately and investigate your claim. 


\title{
Equivalent Design Pressure for Ship Plates Subjected to Moving Slamming Impact Loads
}

\author{
Ling Zhu ${ }^{\text {a, b }}$, Lele Duan ${ }^{c}$, Mingsheng Chen ${ }^{\mathrm{a}, \mathrm{b}, *}$ T.X. Yu ${ }^{\mathrm{c}, \mathrm{d}}$, Preben Terndrup Pedersen ${ }^{\mathrm{c}, \mathrm{e}}$

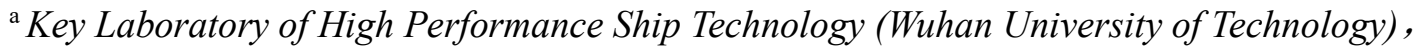 \\ Ministry of Education, Wuhan 430063, PR China \\ ${ }^{\mathrm{b}}$ Collaborative Innovation Centre for Advanced Ship and Deep-Sea Exploration (CISSE), \\ Shanghai 200240, PR China
}

${ }^{c}$ Departments of Naval Architecture, Ocean and Structural Engineering, School of Transportation, Wuhan University of Technology, PR China

${ }^{\mathrm{d}}$ Department of Mechanical and Aerospace Engineering, Hong Kong University of Science and Technology, Clear Water Bay, Kowloon, Hong Kong

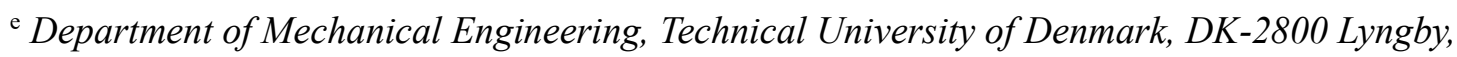
Denmark

\begin{abstract}
When a ship navigates at sea, the slamming impact can generate significant load pulses which move up along the hull plating. The effect of the moving pressure has so far not been explicitly considered in the Rules and Regulations for the Classification of Ships. Based on a modal superposition method and the Lagrange equation, this paper derives analytical solutions to study the elastic dynamic responses of fully clamped rectangular plates under moving pressure impact loads. The spatial variation of the moving slamming impact pressure is simplified to three types of impact loads, i.e. a rectangular pulse, a linearly decaying pulse and an exponentially decaying pulse. The dynamic responses of fully clamped rectangular plates under the moving slamming impact pressure are calculated in order to investigate the influence of the load pulse shapes and moving speed on the plate structural behaviour. It is found that the structural response of the
\end{abstract}

* Corresponding author. Tel.:+86 182-7193-5791

E-mail address: mschen@whut.edu.cn (M. Chen) 
plate increases with the increase of the moving speed. The response of the plate subjected to a moving pressure impact load is smaller than the case when the plate is subjected to a spatially uniform distributed impact load with the same load amplitude and load duration. In order to quantify the effect of the moving speed on the dynamic load, a Dynamic Moving Load Coefficient $(D M L C)$ is introduced as the ratio between the dynamic load factor for the moving impact load and that under the spatially uniform distributed impact load. An expression for $D M L C$ is proposed based on analyses of various scenarios using the developed analytical model. Finally an empirical formula which transforms the moving impact loads to an equivalent static load is proposed.

Keywords: slamming; moving load; analytical solution; Dynamic Moving Load Coefficient $(D M L C)$; equivalent design pressure

\section{Introduction}

When a ship sails in high waves, it often encounters wave slamming impacts which may cause permanent plate deflections and even lead to severe maritime accidents. Zhu [1] summarized the common slamming damage patterns and damage position based on the damage database in Lloyd's Register class. Due to its practical importance, slamming research has attracted the attention of researchers worldwide. There are two main types of responses arising in slamming problems, i.e. global and local responses. In terms of load, global and local loads cannot be separated.

The study of slamming impact can date back to the study of wedge impact loads on seaplane floats during landing by Von Karman [2]. Following his study, Wagner [3] considered the uplift of the wet surface of the fluid and proposed a theory for calculating the slamming pressure of a blunt body impacting into water. In his study, the potential flow theory was applied to calculate the slamming pressure and an analytical formula was derived for quantifying the variation of the slamming pressure with time and position. Watanabe [4] presented a pressure distribution for a plate slanting into the water, which overcomes some of the shortcomings of Wagner's model. 
Faltinsen [5] presented an overview of many water-entry problems in ship and ocean engineering, and concluded that the maximum pressure cannot be used to estimate maximum slamminginduced stresses since the dynamic hydroelastic effects would then become significant under large slamming pressures. He further pointed out that the importance of the local and global structural flexibility is related to the duration of the slam loading, with the strongest effect at small deadrise angle and high impact speed.

Wilson [6] modeled the air cushion layer appearing at the interface during the initial stage of fluid impact and developed an analytical solution by using the matched asymptotic technique. The problem of oblique water entry was also studied by applying the potential flow theory by Bao et al. [7] and Wu and Sun [8]. Seng [9] applied a CFD method to study the distribution of the slamming pressure for a two-dimensional wedge entering the water surface. Recently, more research works have been reported on the subject of hydroelasticity with structural flexibility taken into account in the slamming, see, for example, Wang and Guedes Soares [10].

The random nature of the slamming phenomena has motivated many researchers to study the slamming problems using the statistical tools. To the best knowledge of the authors, the most famous statistical work on slamming was done by Ochi [11-12]. He developed simple formulae for calculating the probability of slamming, which are still widely used today. In addition, Ochi [13] and Ochi and Motter [14] developed design methods for calculating the slamming loads on vessels with arbitrary geometry by using statistical tools. Based on their studies, the slamming pressure can be assumed to be proportional to the square of the relative velocity at the instant of impact. Hence, a factor dependent upon the local section shape, known as the slamming pressure coefficient, is required to calculate the slamming pressure. The pressure coefficients can be obtained from drop tests [15-20], seakeeping model tests and full scale trials, each with its own merits [1]. For wedge impact problems, the slamming pressure coefficient has been obtained from Wagner's model [3] and other theoretical work [21-22]. However, many uncertainties remain in slamming research, such as the wave steepness, disturbed wave profile, air-entrapment, local slamming induced plastic response, square law of relative velocity and effects of structural geometry.

Jones [23] applied a rigid-plastic theoretical method to study the structural damage of ship plating subjected to slamming loads. Zhu and Faulkner [15] adopted a finite difference method 
to analyse the dynamic elastic response of a rectangular plate at flat impact by simplifying the slamming pressure to a spatially uniform distributed triangular pulse. Their numerical results were found to agree well with the strain measurements under flat impact for the wetdeck slamming of twin hull vessels. Paik et al. [24] studied the impact loads caused by slamming or green water by simplifying the slamming pressure to typical idealized impact loads. The elastoplastic response of ship plate under these idealized impact loads were calculated by using finite element method, while the moving nature of slamming pressure was not investigated in their analyses.

The moving nature of the slamming pressures for wedge impact has been well illustrated by a series of drop tests model $[15,25-26]$. As the structure enters the water, the water impact loads move up along the surface of the structure with time. There have been a few studies on the effect of a moving slamming load in recent years. Lv and Grenestedt [27] analytically studied the deformation of ship hull bottom panels. In their study, a linear elastic Euler-Bernoulli beam was used as the representation of the cross section of the bottom panel, and the slamming load was simplified as a high-intensity peak followed by a lower constant pressure, travelling along the beam with constant speed. Their study shows that the maximum dynamic deflection does not differ much from the static counterpart for relatively slow moving slamming load, while the dynamic effect could be significant for faster moving load. Their analytical method was further applied to study the responses of bottom panels against moving slamming loads [28]. In addition, Datta and Siddiqui [29] numerically studied the dynamic response of rectangular plates under the transient hydrodynamic impact loads, with the plate being modeled as Kirchhoff's plate. They established the relationship between the Dynamic Load Factor $(D L F)$ and the wetting time $\tau$, and identified the range of $\tau$, within which the plate has significant dynamic response. They further performed theoretical hydroelastic analysis of axially loaded Timoshenko beams with varying end fixities under hydrodynamic slamming loads [30]. Zhu et al. [31] numerically studied the dynamic elasto-plastic response of ship plates subjected to moving slamming load. They investigated the effects of load duration and moving speed of the moving linearly decaying load on $D L F$. In other fields, the study on the dynamic response of structures subjected to moving loads has been reported by many researchers. Friba [32] applied an integral transform method to derive an analytical solution of a simply supported rectangular plate under a moving concentrated 
force. Alisjahbana [33] proposed an approximate method to calculate the dynamic response of a fully clamped rectangular plate subjected to moving loads.

The current ship design guidance generally simplifies the slamming loads as an equivalent distributed static pressure due to the complexity of the moving nature of slamming load [34-36]. However, the equivalence of such static pressure to the actual slamming pressure has not yet been properly established. In many studies, the slamming load is simplified as a spatially uniform distributed impact load varying only with time. In recent years, some researchers have applied the concept of a moving load to analyse the effect of slamming, and simplified the structural model as a beam or a plate in order to derive the equivalent static loads. It is found that compared with a dynamic, spatially uniform distributed impact load, the moving load shows a much more complicated and inhomogeneous response. If the $D L F$ is calculated based on a spatially uniform distributed slamming pressure, the structural design will tend to be more conservative. This has been reflected in many design appraisal cases. In order to account for the inhomogeneity of the slamming pressure distribution on the ship plates, a simultaneous load factor was introduced in ABS's design guide [37].

Through the analysis of published literature and ship rules, it can be found that the local slamming response is important for ship design. Unfortunately, the effect of the local slamming response is still not well established. Therefore, more research work is needed to deepen the understanding of the effect of moving slamming load on the dynamic response of ship plates. This is the motivation for the present study.

For the wedge impact problem, the water impact load varies with the deadrise angle of the wedge. For deadrise angles less than $3^{\circ}$, as it often happens at bow flare slamming and wet deck slamming, the flat plate panels are subjected to large dynamic spatially uniform distributed pressure pulse, where air cushions are normally involved. It often causes damages to the local plate panels, as examined by Jones [23] and Zhu and Faulkner [15]. Recently, plastic deformations under various pressure pulses and the saturated impulse are studied by Zhu et al. [38-39] and Bai et al. [40]. For deadrise angles larger than about $30^{\circ}$, the spatial distribution of the slamming pressure does not vary much and the velocity of the pressure front is limited [41]. In this case, quasi-static response calculations will often have sufficient accuracy. 
response between these two extremes. That is to study the elastic structural deflections for deadrise angles between $3^{\circ}$ and $30^{\circ}$ where measurements and theoretical studies show a distinct high slamming pressure peak close to the spray root in front of the wetted part of the structure and where the speed of the moving pressure peak is comparable to the width of the structure divided by the lowest natural period of the plating such that the speed of the entering water velocity is important for the structural response. In addition, the present paper presents a procedure to determine the local elastic response of ship hull plating under slamming impact loads taking into account the effect of the moving pressure loading.

In order to study the static equivalence of the dynamic response of a ship plate under water impact load, analytical solutions of the dynamic response of fully clamped rectangular plates surrounded by fluid from one side under spatially uniform distributed impact loads and moving impact loads are presented. Since the hull plate is surrounded by strong structural frames, the boundary conditions of the hull plate are simplified as fully clamped. The slamming load is modelled as a rapidly rising impact load, and the shape of pressure pulse varies with slamming speed and deadrise angle.

There are large uncertainties in the measurement of slamming loads due to the sharp rising of pressures, and the pressure measuring methods used. Various shapes of pressure pulses recorded from the experiments have been reported in the literature and the effect of these different shapes of pressure pulses is not well understood. For this reason, three typical forms of impact loads are analyzed in the present study: a rectangular pulse, a linearly decaying pulse and an exponentially decaying pulse.

The governing equations are derived by combining the modal superposition method and Lagrange's equation. The results are presented in terms of the dynamic load coefficients such as the $D L F$ and $D M L C . D L F$ is the ratio between the dynamic response of the structure under the dynamic load and the response under a distributed static pressure with the same pressure amplitude as the dynamic load. $D M L C$ denotes the ratio between the $D L F$ under the moving impact load (i.e. $D L F m$ ), and that under the spatially uniform distributed impact load (i.e. $D L F d$ ), which is introduced to quantify the effect of moving load on the structural response. A formula of the maximum $D M L C$ is derived in this study. In this way, the current method can be used to transform the moving impact loads to an equivalent static load, and thus the dynamic structural 
analysis of ship plate subjected to moving slamming loads can be greatly simplified.

\section{Simplified analytical model of the impact load on rectangular plate}

\subsection{Simplifications and assumptions of the ship bottom slamming problem}

In this paper, the ship hull panel slamming problem is simplified as a rectangular plate subjected to a slamming impact load $P(x, y, t)$ which moves with a constant velocity $c_{x}$ from one end to the other, as shown in Fig. 1. Since the ship bottom plates are surrounded by the strong structural frames, the plates are here simplified as a fully clamped rectangular plate. The moving speed $c_{x}$ can be derived based on the relative entering water velocity $V$ and deadrise angle of the wedge as [3].

$$
c_{x}=\frac{\pi V}{2 \sin \beta}
$$

The slamming impact load can be simplified as three typical forms of pulse loads: a rectangular pulse, a linearly decaying pulse and an exponentially decaying pulse, as shown in Fig. 2. These idealized pressure models can be described based on a few characteristic parameters such as the peak pressure $P_{m}$ and load duration $t_{d}$. Since the water impact pressure varies very little across a single plate panel, it is assumed that the amplitude and load shape of water impact load within one panel are constant, and the water impact load moves with a constant speed along the hull plate. The dynamic response for the three typical pulse loads uniformly applied on the plate and the dynamic response for these pulse loads moving along the plate will be calculated and compared. Fig. 3 illustrates the simplified model for the fully clamped rectangular plate subjected to three types of moving pulse loads. In the present study, only the elastic behaviour of the plate is considered. The dimensions and material parameters of the plate are summarized in Table 1.

Table 1. Dimensions and material parameters of the plate

\begin{tabular}{|l|l|}
\hline Plate Dimension $a \times b \times h[\mathrm{~mm}]$ & $600 \times 1800 \times 12$ \\
\hline Elastic modulus $E[\mathrm{Gpa}]$ & 206 \\
\hline Plate density $\rho\left[\mathrm{kg} / \mathrm{m}^{3}\right]$ & 7850 \\
\hline Poisson's ratio $v$ & 0.3 \\
\hline
\end{tabular}


200

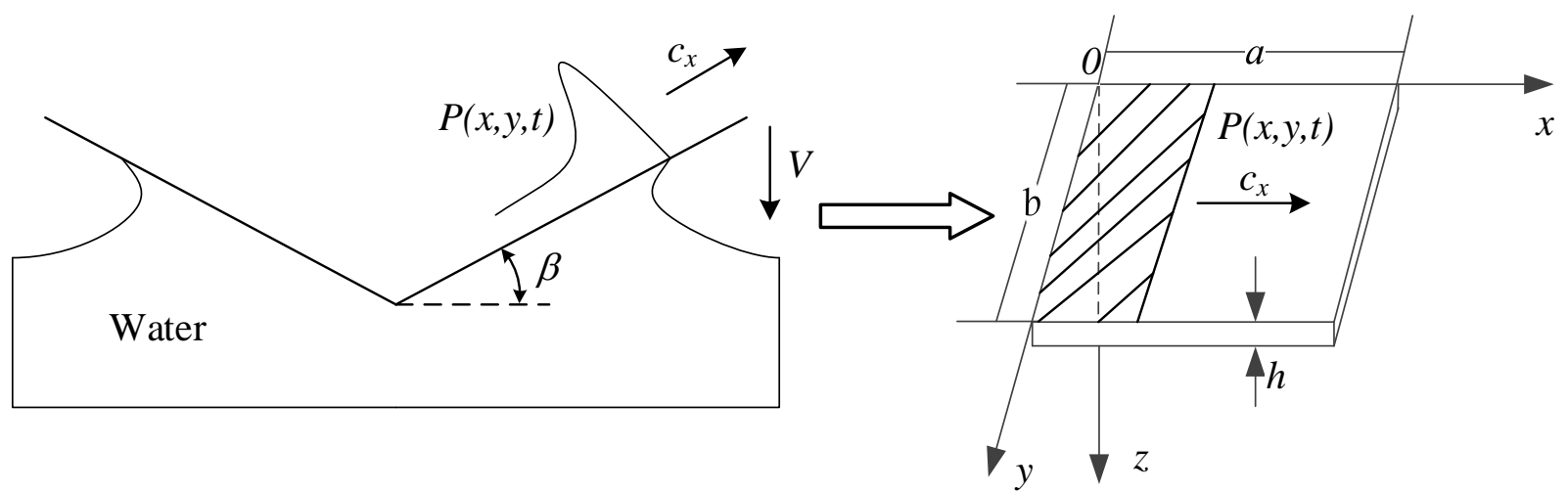

Fig. 1. Simplified model of water impact

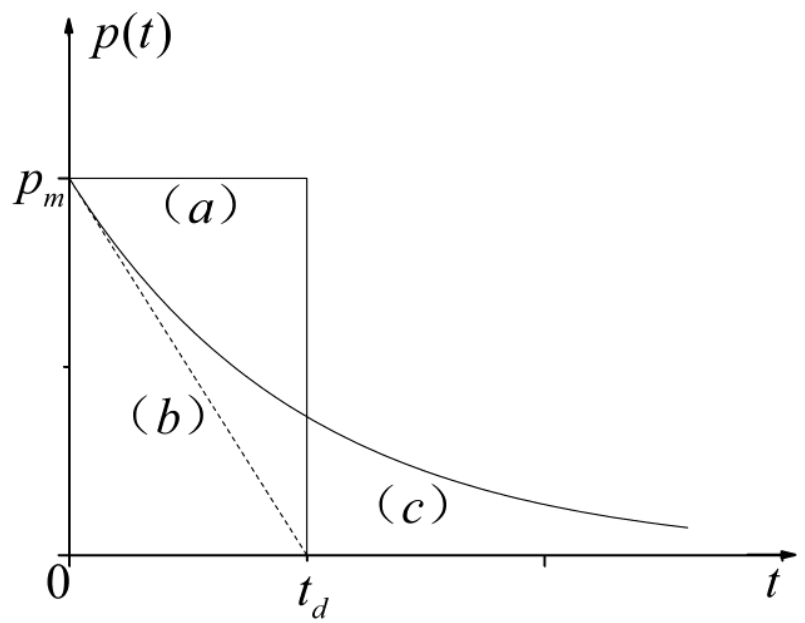

Fig. 2. Three types of spatially uniform distributed pulse loads ( $a$ : rectangular pulse; $b$ : linearly decaying pulse; $c$ : exponentially decaying pulse)

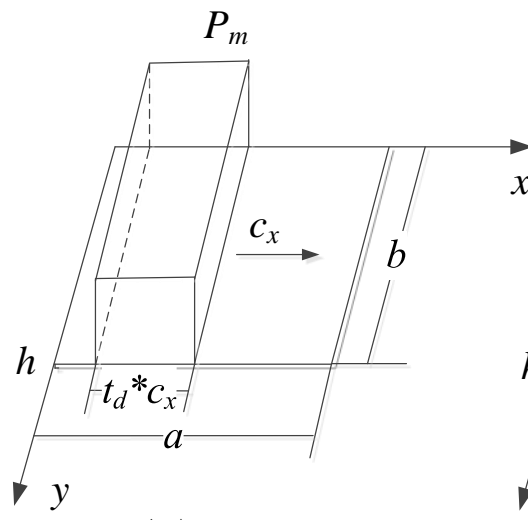

(a)

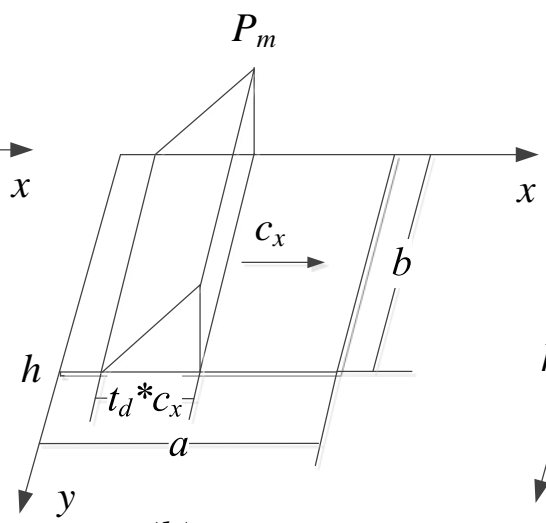

(b)

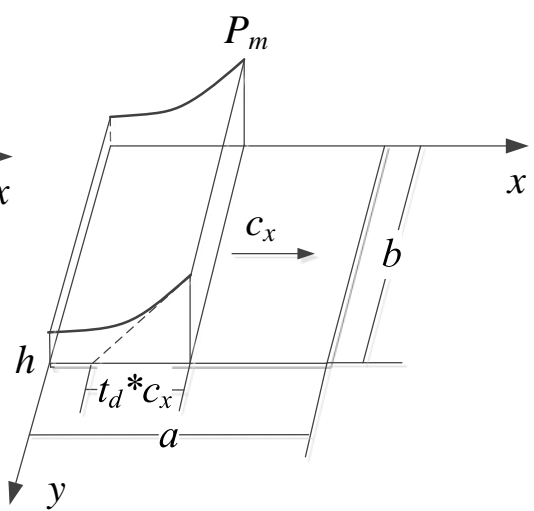

(c)

Fig. 3. Simplified model of the fully clamped rectangular plate subjected to moving pulse load $P(x, y, t)$ with a constant travelling speed $c_{x}$ ( $a$ : moving rectangular pulse; $b$ : moving linearly decaying pulse; $c$ : moving exponentially decaying pulse)

Based on the plate coordinate system shown in Fig.1, the lateral deflection of the plate under 
the water impact pressure load $P(x, y, t)$ can be expressed as $Z(x, y, t)$, where $x(0<x<a)$ and $y$ $(0<y<b)$ are positions within the plate and $t$ denotes time.

The dynamic deflection will be represented by a summation of the modal components:

$$
Z(x, y, t)=\sum_{i=1}^{\infty} \sum_{j=1}^{\infty} A_{i j} W_{i j}(x, y)
$$

where $W_{i j}(x, y)$ is the applied modal shapes.

Lagrange's equation is applied to derive the governing differential equations:

$$
\frac{d}{d t}\left(\frac{\partial K}{\partial \dot{A}_{i j}}\right)+\frac{\partial U}{\partial A_{i j}}=\frac{\partial W_{e}}{\partial A_{i j}}
$$

where $K$ is the kinetic energy of the plate, $K=\frac{1}{2} m^{\prime} \int_{0}^{a} \int_{0}^{b} \dot{Z}^{2} d x d y ; U$ is the strain energy; $W_{e}$ is the work made by the external pressure force; $A_{i j}$ is the modal amplitude, which varies with time; $m^{\prime}$ is the total mass per unit area of the plate, which includes the mass of plate, $m$, and the added mass of water, $m_{a}$ and is assumed to be constant.

According to Ref. [42], the added mass of a fully clamped plate surrounded by fluid from one side can be expressed as follows:

$$
m_{a}=\rho_{w} a \mu(a / b)
$$

where $\rho_{w}$ is the water density and $\mu(a / b)$ is the added mass coefficient mainly depending on the shape of oscillations of the plate.

It needs to be noted that there has no added mass term at the beginning of the slamming event since the ship plate is essentially dry before slamming start. In practical slamming problem, the ship plate would move into the water and thus the added mass calculation by Eq. (4) may introduce uncertainties that need to be explored in future. However, for the simplified model analyzed here, this equation can be very useful.

Since the velocity is given by

$$
\dot{Z}(x, y, t)=\sum_{i=1}^{\infty} \sum_{j=1}^{\infty} \dot{A}_{i j} W_{i j}(x, y)
$$

the kinetic energy of the plate is expressed as

$$
K=\frac{1}{2} m^{\prime} \int_{0}^{a} \int_{0}^{b}\left[\sum \dot{A}_{i j} W_{i j}(x, y)\right]^{2} d x d y
$$

$$
K=\frac{1}{2} m^{\prime} \int_{0}^{a} \int_{0}^{b}\left[\sum \dot{A}_{i j}^{2} W_{i j}^{2}(x, y)\right] d x d y+m^{\prime} \int_{0}^{a} \int_{0}^{b}\left\{\sum\left[\dot{A}_{i j} W_{i j}(x, y)\right]\left[\dot{A}_{m n} W_{m n}(x, y)\right]\right\} d x d y
$$


Using the orthogonal modes $W_{i j}$ associated with the free vibrations of the clamped plate, see Appendix A, the series in the second term of equation (6b) is 0 . Thus, the kinetic energy of the plate is

$$
\begin{aligned}
K & =\frac{1}{2} m^{\prime} \int_{0}^{a} \int_{0}^{b}\left[\sum \dot{A}_{i j}{ }^{2} W_{i j}{ }^{2}(x, y)\right] d x d y \\
& =\frac{1}{2} m^{\prime} \sum_{i=1}^{\infty} \sum_{j=1}^{\infty} \dot{A}_{i j} \int_{0}^{a} \int_{0}^{b} W_{i j}{ }^{2}(x, y) d x d y
\end{aligned}
$$

240 and

$$
\frac{d}{d t} \frac{\partial K}{\partial \dot{A}_{i j}}=m^{\prime} \ddot{A}_{i j} \int_{0}^{a} \int_{0}^{b} W_{i j}^{2}(x, y) d x d y
$$

The strain energy of the plate can be expressed as

$$
U=\frac{E h^{2}}{24\left(1-v^{2}\right)} \int_{0}^{a} \int_{0}^{b}\left[\left(\frac{\partial^{2} Z}{\partial x^{2}}\right)^{2}+\left(\frac{\partial^{2} Z}{\partial y^{2}}\right)^{2}+2 v \frac{\partial^{2} Z}{\partial x^{2}} \frac{\partial^{2} Z}{\partial y^{2}}+2(1-v)\left(\frac{\partial^{2} Z}{\partial x \partial y}\right)^{2}\right] d x d y
$$

The work made by the slamming impact load can be obtained as follows

$$
W_{e}=\int_{0}^{a} \int_{0}^{b} P(x, y, t)\left[\sum_{i=1}^{\infty} \sum_{j=1}^{\infty} \dot{A}_{i j} W_{i j}(x, y)\right] d x d y
$$

which leads to

$$
\frac{\partial W_{e}}{\partial A_{i j}}=\int_{0}^{a} \int_{0}^{b} P(x, y, t) W_{i j}(x, y) d x d y
$$

Based on Eq. (2), the following expression can be derived:

$$
m^{\prime} \ddot{A}_{i j} \int_{0}^{a} \int_{0}^{b} W_{i j}^{2}(x, y) d x d y+\frac{\partial U}{\partial A_{i j}}=\int_{0}^{a} \int_{0}^{b} P(x, y, t) W_{i j}(x, y) d x d y
$$

Since the orthogonal expansion modes $W_{i j}$ are the solutions to the self-adjoint homogenous part of Eq. (10), the un-coupled inhomogeneous differential equations can be obtained [43]:

$$
\ddot{A}_{i j}+\omega_{i j}^{2} A_{i j}=\frac{\int_{0}^{a} \int_{0}^{b} P(x, y, t) W_{i j}(x, y) d x d y}{m^{\prime} \int_{0}^{a} \int_{0}^{b} W_{i j}^{2}(x, y) d x d y}
$$

By expressing the numerator of the right term of Eq. (11) as the load-time function $f(x, y, t)$ and the time independent load distribution function $P_{1}(x, y)$, the following equation is derived

$$
\int_{0}^{a} \int_{0}^{b} P(x, y, t) W_{i j}(x, y) d x d y=g(x, y, t)=f(x, y, t) P_{1}(x, y)
$$

which leads to

$$
\ddot{A}_{i j}+\omega_{i j}^{2} A_{i j}=\frac{f(x, y, t) P_{1}(x, y)}{m^{\prime} \int_{0}^{a} \int_{0}^{b} W_{i j}^{2}(x, y) d x d y}
$$

In Eq. (12b), the modal amplitude $A_{i j}$ can be expressed as 


$$
A_{i j}=A_{i j}^{*}(D L F)_{i j}
$$

where $A^{*}{ }_{i j}$ is the time independent term determined from:

$$
A^{*}{ }_{i j}=\frac{P_{1}(x, y)}{\omega_{i j}^{2} m^{\prime} \int_{0}^{a} \int_{0}^{b} W_{i j}^{2}(x, y) d x d y}
$$

and $(D L F)_{i j}$ is the time varying dynamic load factor for the equivalent un-coupled one-degree system of the $i j$-th mode. This component load factors can be calculated from the following convolution integral:

$$
(D L F)_{i j}=\omega_{i j} \int_{0}^{t} f(x, y, \tau) \sin \omega_{i j}(t-\tau) d \tau
$$

The elastic plate deflection $Z(x, y, t)$ can then be expressed as

$$
Z(x, y, t)=\sum_{i=1}^{\infty} \sum_{j=1}^{\infty} A_{i j} W_{i j}(x, y)=\sum_{i=1}^{\infty} \sum_{j=1}^{\infty} A_{i j s t}(D L F)_{i j} W_{i j}(x, y)
$$

\subsection{Verification of the proposed procedure}

The largest contribution to structural deformations comes from the first flexible modes with the lowest natural periods. The contribution from the higher frequency modes is less significant. To find a balance between the accuracy of the results and computational efficiency, we shall consider the plate described in Section 2.1 with the highest natural period $T=11 \mathrm{~ms}$ subjected to a rectangular pressure which has an amplitude of $P_{m}$, a pressure duration of $t_{d}$ and a speed of $c_{x}$.

Fig. 4 shows the time series of the deflection at the central point of the plate obtained by applying different numbers of modes. It can be observed from Fig. 4 that the deflection at the central point of the plate remains unchanged when the number of modes reaches eight. Fig. 5 shows the comparisons between the present results and finite element analyses using ABAQUS for both rectangular and exponentially decaying pulses. It can be found that the present results agree well with the numerical results using ABAQUS for both cases. In addition, it needs to be noted that a similar good accuracy is achieved for the exponentially decaying pressure using 8 modes. Therefore, for the following calculations, only the first eight modes are applied. 


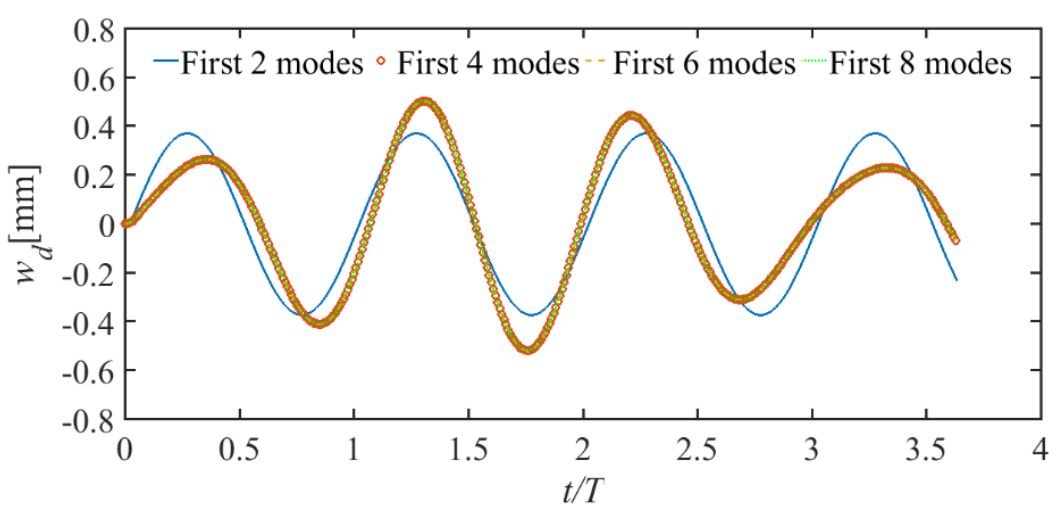

(a) Spatially uniform distributed rectangular pulse with $t_{d}=0.1 T$

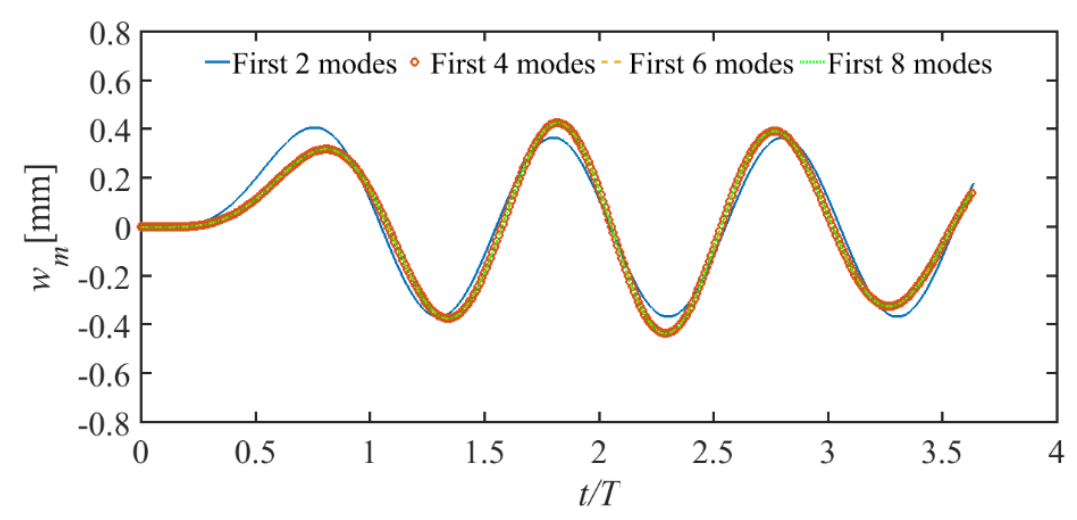

(b) Moving rectangular pulse with $t_{d}=0.1 T$ at speed $c_{x}=54.5 \mathrm{~m} / \mathrm{s}$

Fig. 4 Dynamic deflection at the central point of the fully clamped rectangular plate under spatially uniform distributed rectangular pulse (a) and moving rectangular pulse (b) with $P_{m}=100 \mathrm{kPa}$

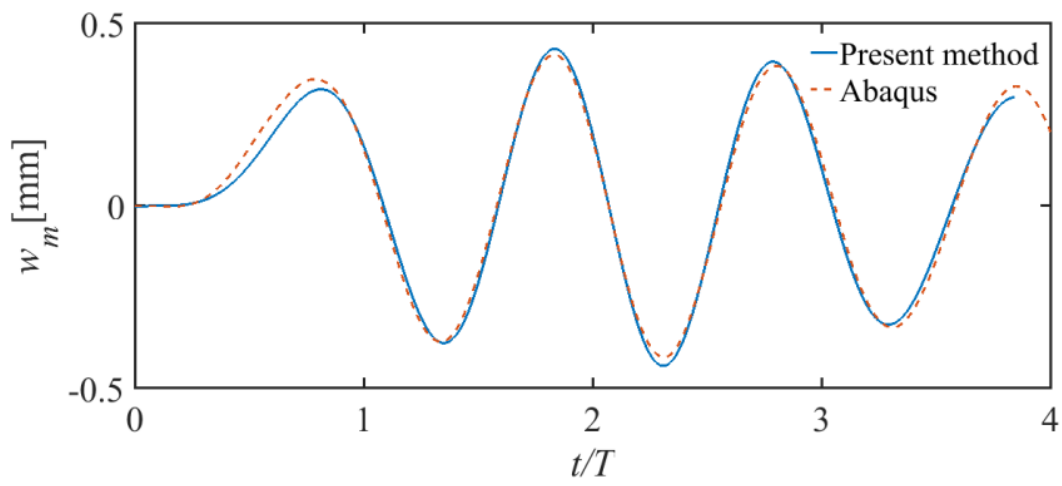

(a) The moving rectangular pulse 


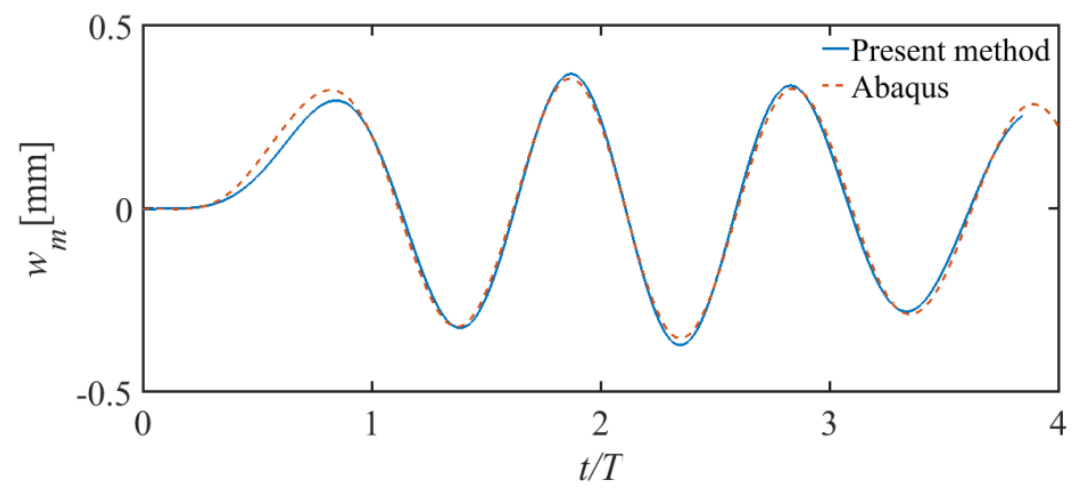

(b) The moving exponentially decaying pulse

Fig. 5. Time history of the deflection at the central point of the fully clamped rectangular plate subjected to moving load with $P_{m}=100 \mathrm{kPa}$ and $t_{d}=0.1 T$ at speed $c_{x}=54.5 \mathrm{~m} / \mathrm{s}$

\section{Results and discussions}

In the following numerical examples, the dynamic response of the ship plate under three types of moving pulses is investigated. The natural velocity is defined as the ratio between the length of the plate in the direction of the moving load and the highest natural period of the free vibration of the plate, $T$, i.e. $c_{0}=a / T$. Moving speeds between $0.2 c_{0}$ and $10 c_{0}$ with an increment of $0.2 c_{0}$ are investigated.

In this study, $a=600 \mathrm{~mm}$, and $T=11 \mathrm{~ms}$ for the fully clamped rectangular plate surrounded by fluid from one side. The impact load duration $t_{d}$ varies from $0.1 T$ to $4 T$ with an increment of $0.1 T$. In order to ensure that the deflection of the rectangular plate is in the elastic range, the peak pressure is chosen as $P_{m}=100 \mathrm{kPa}$.

\subsection{Determination of the equivalent static design pressure for the ship plate under moving rectangular pulse}

Firstly, the clamped rectangular plate subjected to the moving rectangular pulse with constant traveling speed $c_{x}$ is considered. When the spatial length of the slamming pulse $l_{d}=c_{x} t_{d}<a$, depending on the position of the rectangular pulse, the plate response can be classified into four different stages as shown in Fig. 6: (a) arrival of the pulse on the plate, (b) the pulse fully applied on the plate, (c) departure of the pulse from the plate, and (d) the subsequent free vibration. 
312 In this case the load is expressed as

$$
P(x, y, t)=\left[H\left(x-c_{x}\left(t-t_{d}\right)\right)-H\left(x-c_{x} t\right)\right] p_{m}
$$

314 where $H$ is the Heaviside step function, $H(x)= \begin{cases}0, & x<0 \\ 1, & x \geq 0\end{cases}$

(a) When $0<t<t_{d}$

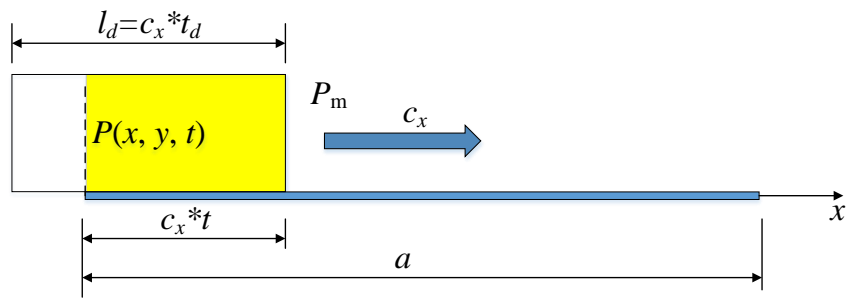

(b) When $t_{d}<t<a / c_{x}$

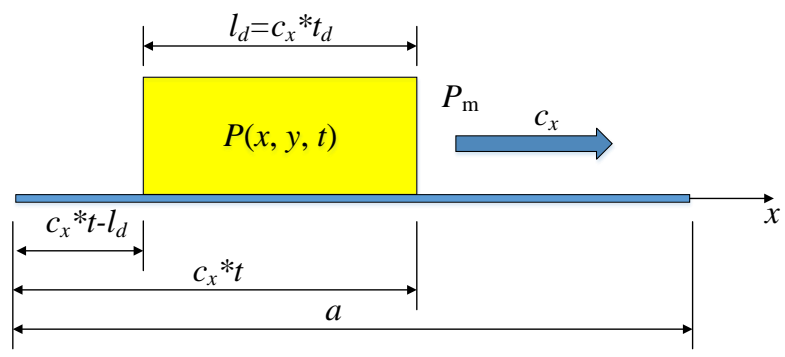

(c) When $a / c_{x}<t<t_{d}+a / c_{x}$

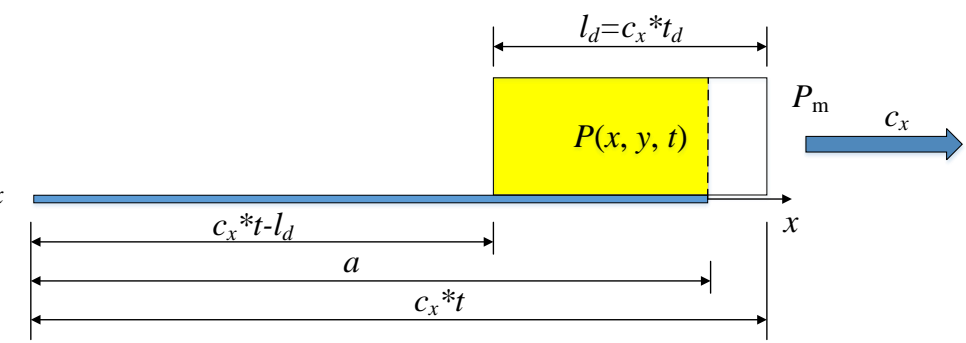

(d) When $t_{d}+a / c_{x}<t$

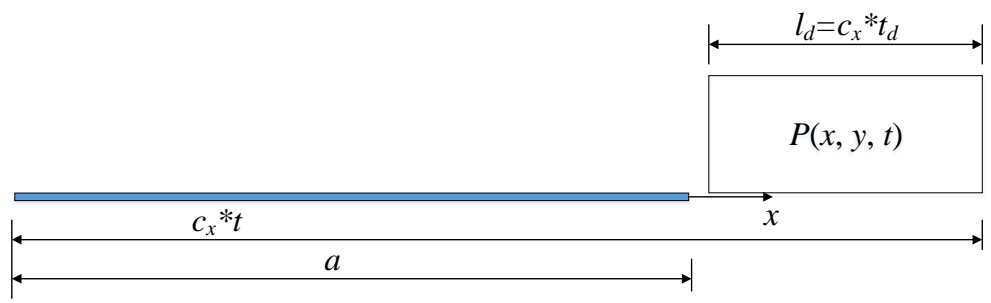

Fig. 6. Evolution of the rectangular pulse moving on the plate

317 The solutions to the dynamic responses of a rectangular plate under moving rectangular pulse

318 are summarised in Appendix B. The time series of the dynamic deflection at the central point of

319 the clamped rectangular plate under both the moving rectangular pulse and spatially uniform

320 distributed rectangular pulse are shown in the Fig. 7. A time delay of the deflection peak is

321 observed for the moving rectangular pulse. The maximum deflection at the central point of the

322 plate subjected to a moving rectangular pulse is smaller than the case subjected to a spatially

323 uniform distributed rectangular pulse. 


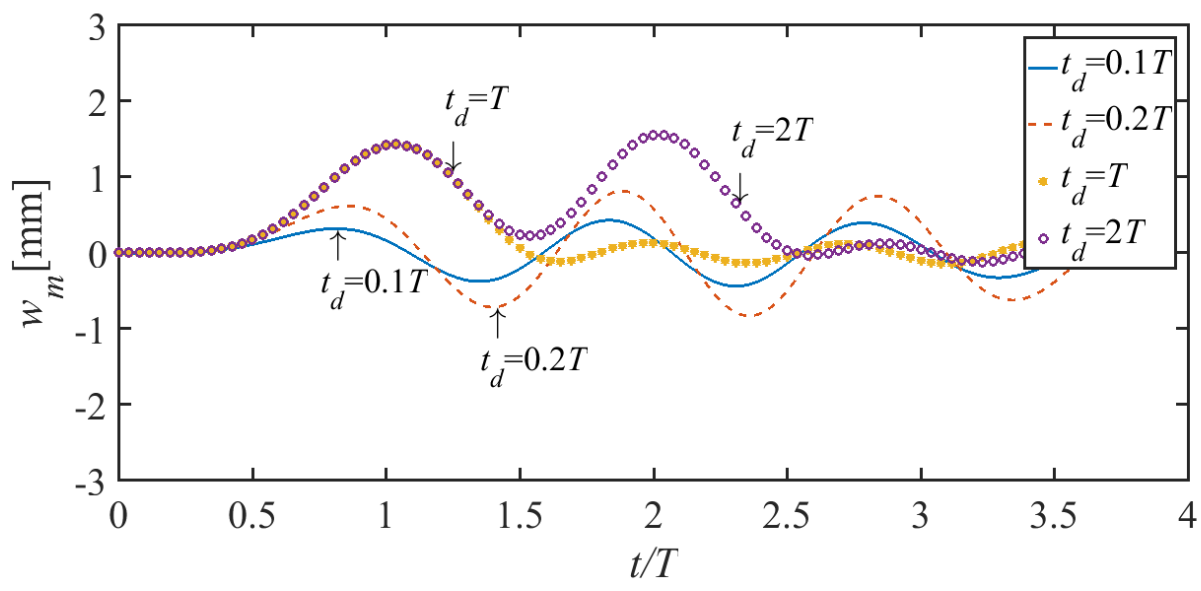

(a) Moving rectangular pulse at speed $c_{x}=54.5 \mathrm{~m} / \mathrm{s}$

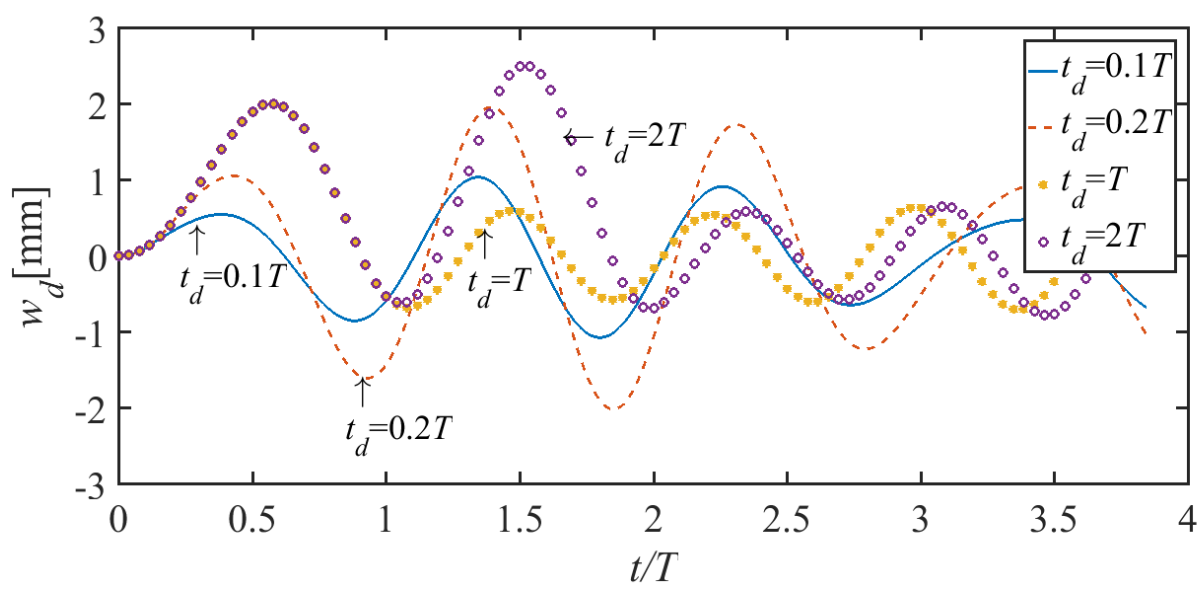

(b) Spatially uniform distributed rectangular pulse

Fig. 7. Dynamic deflection at the central point of the fully clamped rectangular plate subjected to the pulse load with $P m=100 \mathrm{kPa}$

Fig. 8 shows an illustration of the plate subjected to static pressure, spatially uniform distributed rectangular pulse load and a moving rectangular pulse load. For the moving pulse load, if the moving speed is zero, the load would not move from one side of the plate to its other side, which means the plate would not experience any load and thus its response is zero. When the moving speed is large enough to cover the whole plate within an instant, the effect of the moving pulse load can be considered to be equal to that of the "spatially uniform distributed pulse load". The dynamic load factor $D L F d$ is defined as the ratio between the maximum dynamic deflection at the plate center under spatially uniform distributed pulse load (i.e. $\max \left|w_{d}\right|$ ) and the static deflection at plate center (i.e. $w_{s}$ ) under static pressure with the same load amplitude:

$$
D L F d=\max \left|w_{d}\right| / w_{s}
$$


The dynamic load factor under moving load $D L F m$ is defined as the ratio of the maximum dynamic deflection at the plate center under moving pulse load $\max \left|w_{m}\right|$ and the static deflection at the plate center $w_{s}$ under a static pressure with the same load amplitude:

$$
D L F m=\max \left|w_{m}\right| / w_{s}
$$

In order to identify the effect of the moving load, a Dynamic Moving Load Coefficient $(D M L C)$ is defined here:

$$
D M L C=D L F m / D L F d=\frac{\max \left|w_{m}\right|}{\max \left|w_{d}\right|}
$$

Based on the above coefficients, one can easily simplify the moving slamming impact loads to either an equivalent spatially uniform distributed pulse load or an equivalent static load:

$$
P_{d}=D M L C * P_{m}
$$

$$
P_{s}=D L F m * P_{m}
$$

where $P_{m}$ is the magnitude of the moving slamming load; $P_{d}$ and $P_{s}$ are the magnitudes of the equivalent spatially uniform distributed pulse load and equivalent static load, respectively.

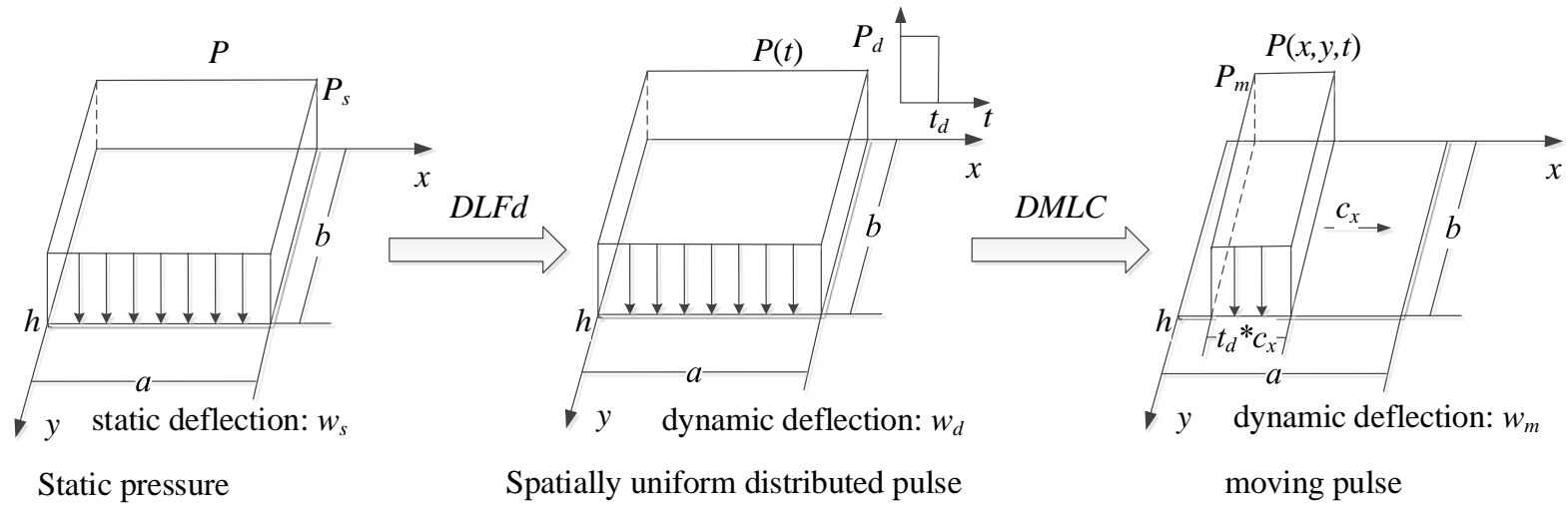

Fig. 8. Simplified model of the rectangular plate subjected to different types of load

The dimensionless moving speed $\bar{c}$ is defined as the ratio between load moving speed and the natural velocity $c_{0}, \quad \bar{c}=c_{x} / c_{0}$. The dimensionless load duration $\bar{t}_{d}$ is defined as the ratio between the impact load duration and the highest natural period of the free vibration of the plate $T$, i.e. $\bar{t}_{d}=t_{d} / T$. Fig. 9 shows the variation of $D L F m$ with $\bar{t}_{d}$ for the clamped rectangular plate subjected to both the moving rectangular pulse and spatially uniform distributed rectangular pulse. It shows that when the dimensionless moving speed $\bar{c}$ is less than 0.6 , the maximum $D L F m$ is less than 1.1. The results clearly show that the maximum $D L F m$ will not be less than 
one if the moving load duration is long enough for the moving rectangular pulse to completely cover the plate. When $\bar{c} \leq 0.6$, the maximum $D L F m$ is between 1 and 1.1. It should be noted that two plateaus appear in the curve for $D L F m$ as a function of the load duration when $\bar{c}=1$, while several plateaus appear when $\bar{c}>1.4$. The reason of this phenomenon is probably due to the fact that more vibration modes of the rectangular plate are excited with the increase of moving speed.

It is clearly shown in Fig. 9 that $D L F m$ increases with the increase of the moving speed, while $D L F m$ is always smaller than $D L F d$ and gradually approaching it with the increase of the moving speed. The response due to the moving rectangular pulse reflects the non-uniformity of the load distribution. As shown in Eq. (20), the Dynamic Moving Load Coefficient (DMLC) defined as the ratio between $D L F m$ and $D L F d$ reflects the effect of the motion of the load. For the moving rectangular pulse, DMLC is calculated using the data in the plateau region. For example, $D M L C=0.944$ when $\bar{c}=3 ; D M L C=0.995$ when $\bar{c}=10 ;$ when $c_{x}=c_{L}=\sqrt{E / \rho}, D M L C=1$. Fig. 10 shows the relationship between $D M L C$ and the dimensionless moving speed $\bar{c}$.

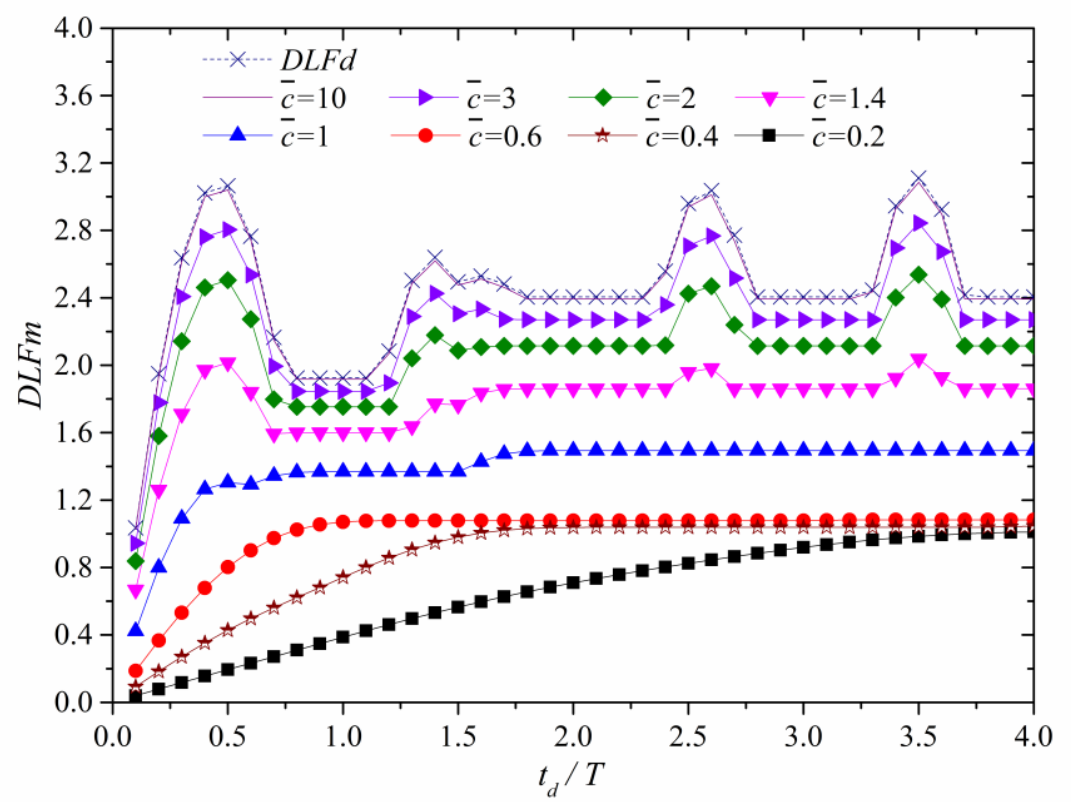

Fig. 9. Variation of $D L F m$ with dimensionless load duration $t_{d} / T$ for the fully clamped rectangular plate subjected to both the moving rectangular pulse and spatially uniform distributed rectangular pulse

In order to make $D M L C$ convenient to use by designers, an empirical formula for $D M L C$ is fitted

$$
D M L C=\left\{\begin{array}{lr}
0.4, & 0<\bar{c} \leq 0.6 \\
1-1.28 \exp [-(\bar{c} / 0.8)], & 0.6<\bar{c}
\end{array}\right.
$$




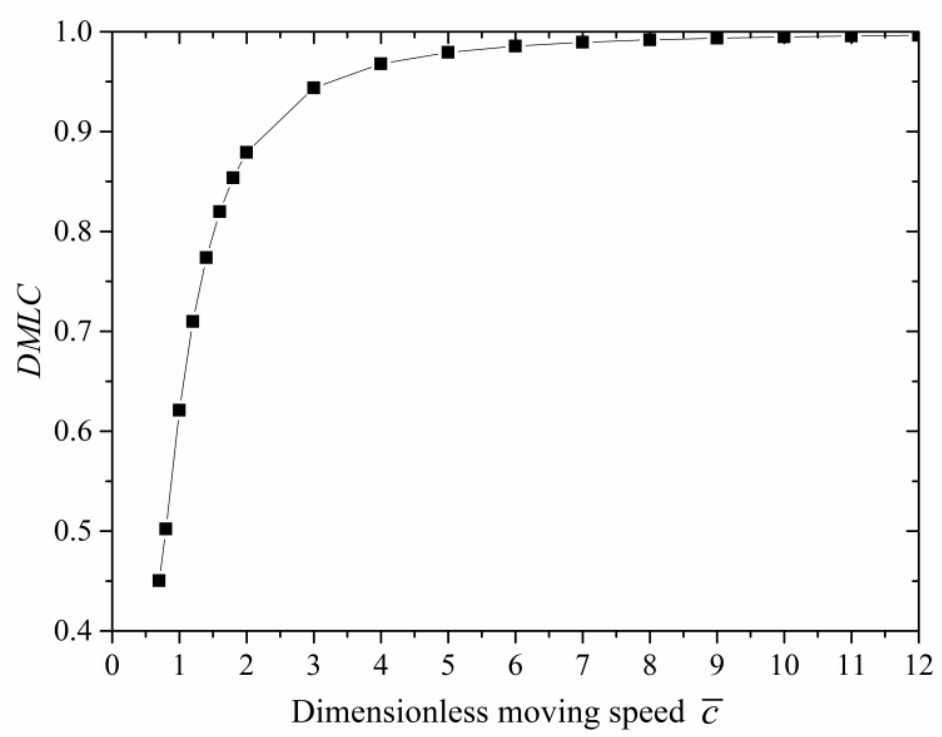

Fig. 10. Variation of $D M L C$ with dimensionless moving speed $\bar{c}$ of the rectangular plate subjected to the moving rectangular pulse

3.2 Influence of pulse load types on the equivalent static pressure

For the case with the fully clamped rectangular plate under the moving linearly decaying pulse $P(x, y, t)$ at constant speed $c_{x}$ (see Fig. $\left.3(b)\right)$, the load can be expressed as:

$$
P(x, y, t)=\frac{p_{m}}{l_{d}}\left(x-c_{x} t+l_{d}\right)\left[H\left(x-c_{x}\left(t-t_{d}\right)\right)-H\left(x-c_{x} t\right)\right]
$$

For the case with the fully clamped rectangular plate under the moving exponentially decaying pulse $P(x, y, t)$ at constant speed $c_{x}$ (see Fig. $\left.3(c)\right)$, the load is

$$
P(x, y, t)=H\left(c_{x} t-x\right) p_{m} \exp \left[\left(x-c_{x} t\right) /\left(c_{x} t_{d}\right)\right]
$$

The dynamic responses of the plate under the moving linearly or exponentially decaying pulse are calculated using the same process as the moving rectangular pulse.

Fig. 11 compares the values of $D L F m$ of the plate subjected to different types of moving pulses at constant speed $c_{0}, 2 c_{0}$ and $12 c_{0}$, where $\bar{I}=\frac{I}{p_{m} \times T}$ represents the dimensionless impulse, and $I=\int_{0}^{8 T} p(t) d t$. It shows that when the impulse remains the same, the $D L F m$ under the rectangular pulse is larger than that under the linearly decaying pulse and the exponentially decaying pulse. By comparing the three figures $(a, b, c)$ in Fig. 11, it is seen that DLFm under the moving exponentially decaying pulse increases monotonically with the pulse duration. On the other hand, 
when the moving speed $c_{x}=c_{0}, D L F m$ for the moving rectangular and linearly decaying pulses tends to become nearly constant with the increase of the pulse duration. However, a sharp peak 402 in $D L F m$ is observed for the moving speed $c_{x}=2 c_{0}$ and $c_{x}=12 c_{0}$, if the dimensionless impulse is 403 less than 0.6. This implies that the increased moving speed will induce resonance of the 404 rectangular plate.

405 Fig. 12 shows the variation of the ratio between the dynamic load factor for the moving impact 406 load and that under the spatially uniform distributed impact load $D M L C$ with the dimensionless 407 moving speed under the three different types of moving pulses, which indicates that $D M L C s$ are 408 very close to each other and that $D M L C$ increases with the increase of the moving speed. 409 Therefore, the fitted formula under the moving rectangular pulse can be applied to the three types 410 of moving pulses for the engineering design purpose.

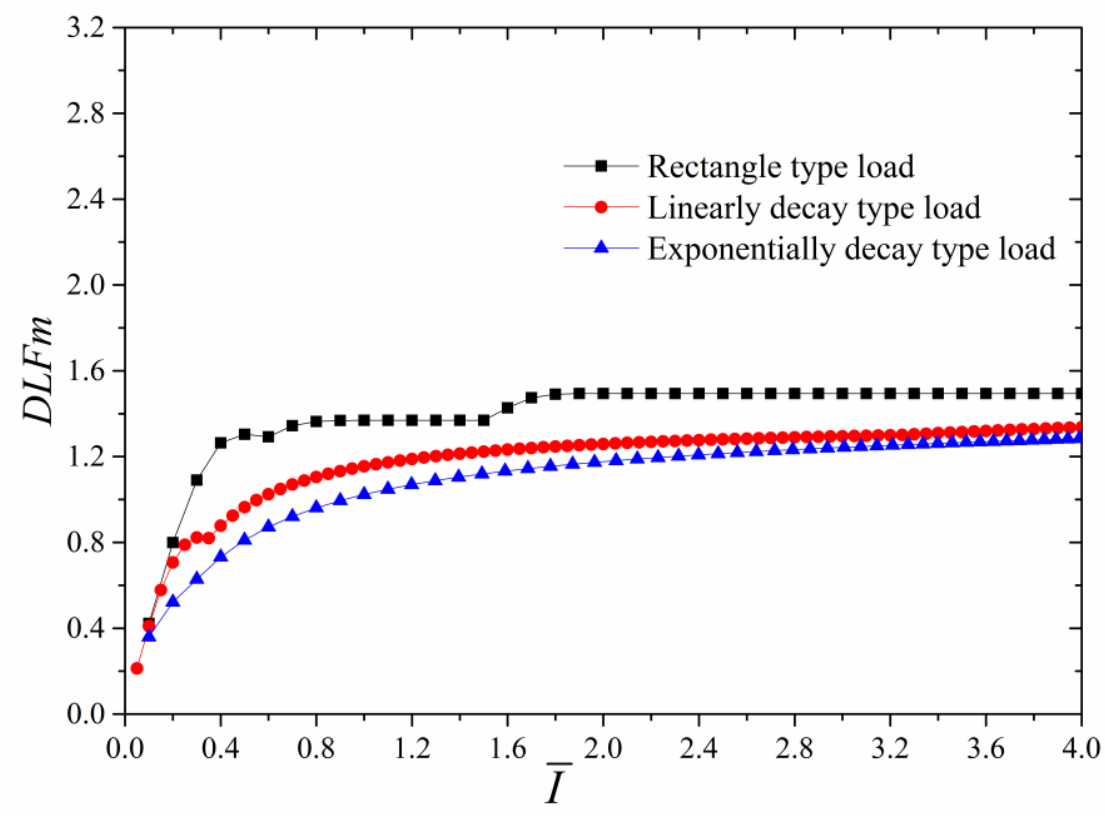

(a) $c_{x}=c_{0}$ 


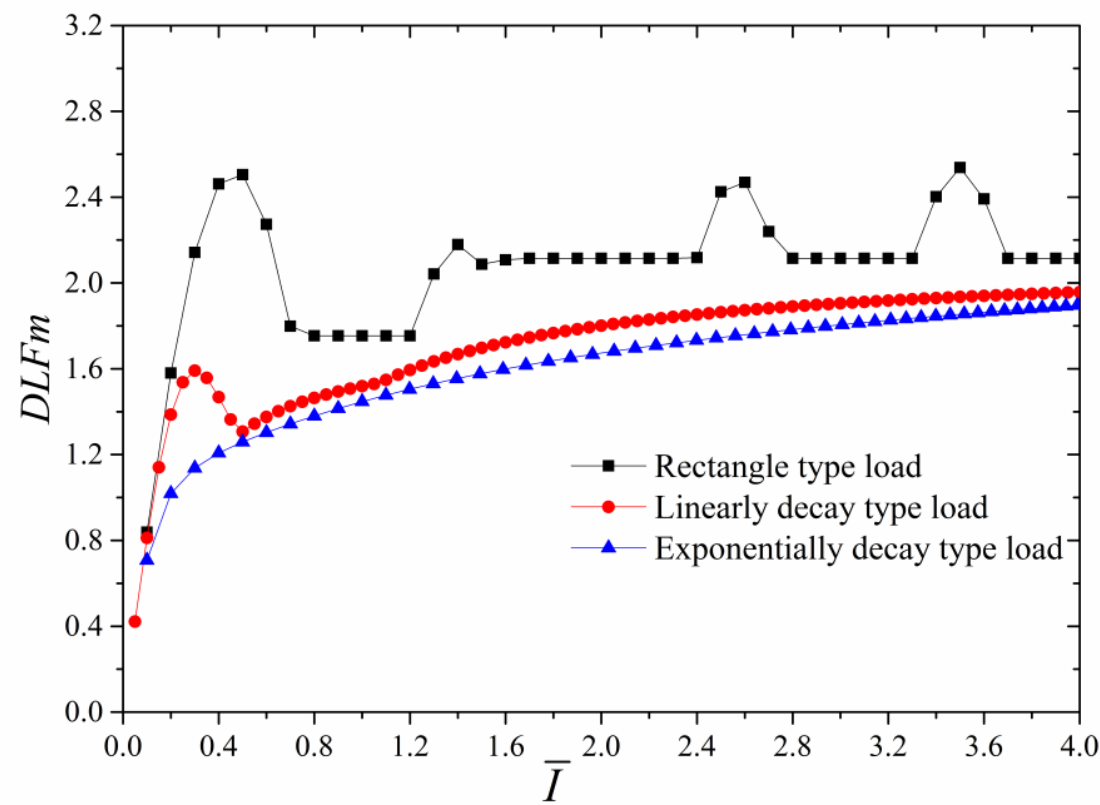

\section{(b) $c_{x}=2 c_{0}$}

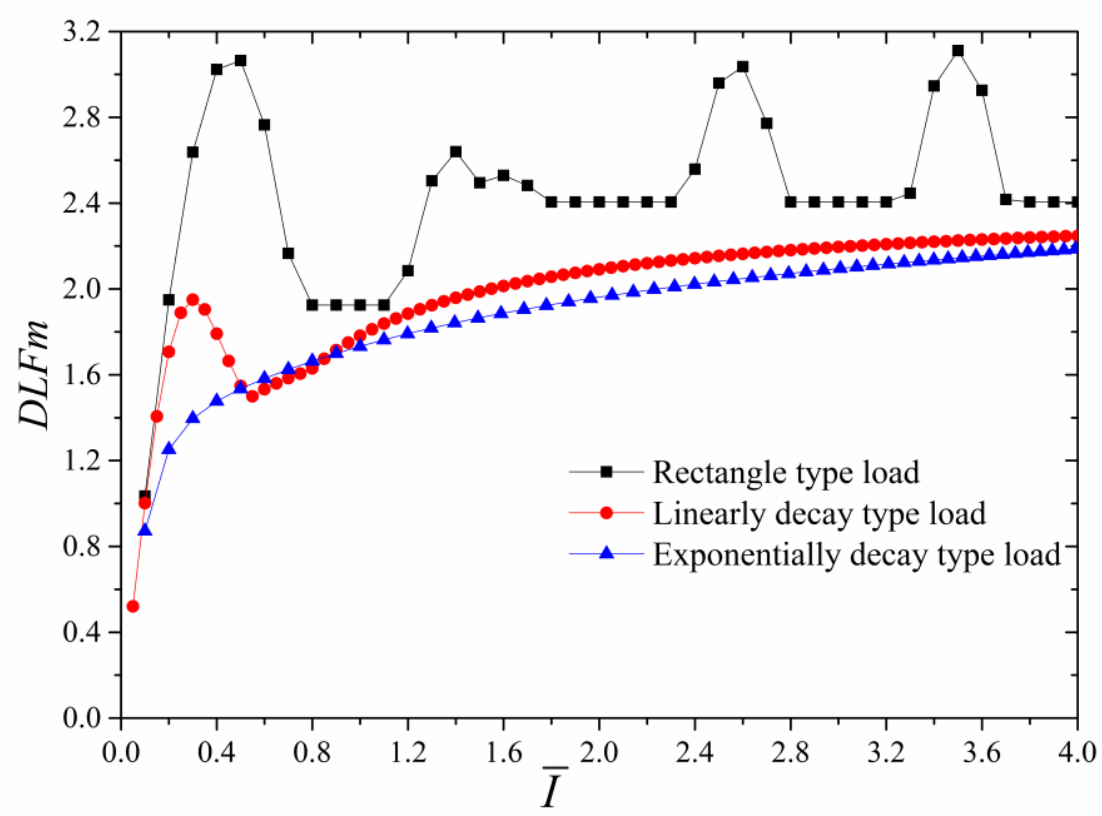

Fig. 11. DLFm versus dimensionless impulse $\bar{I}$ for various moving pulses 


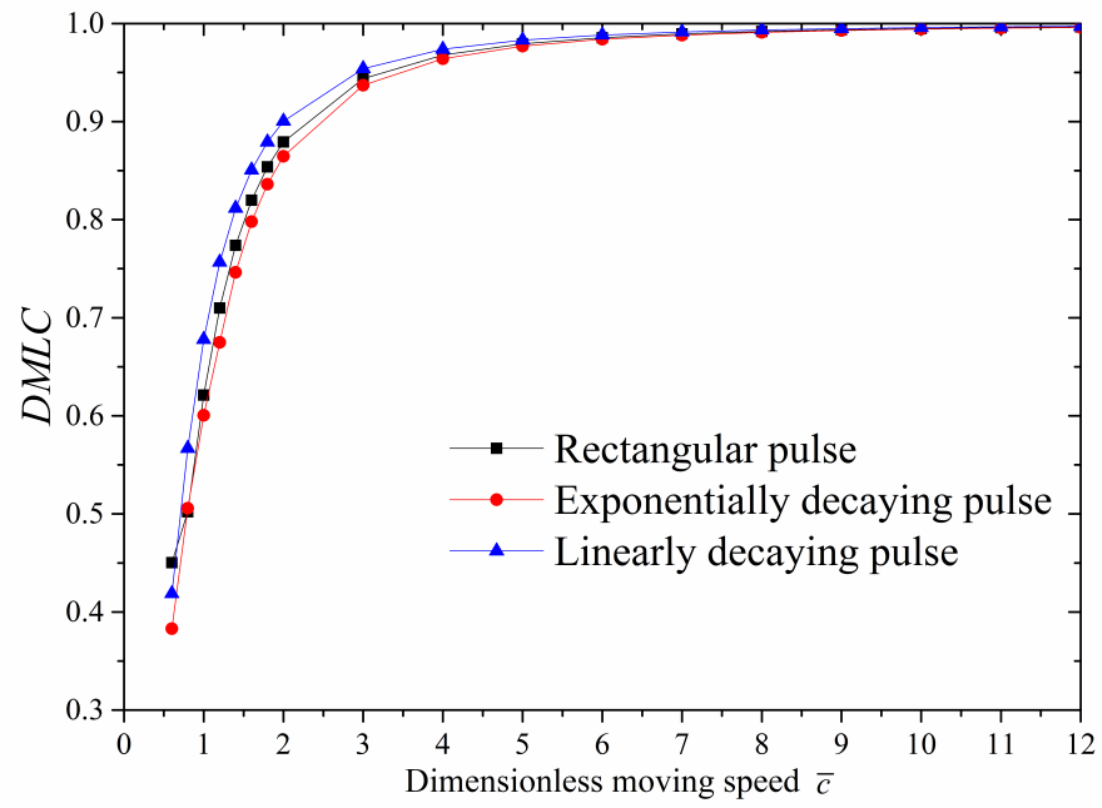

Fig. 12. $D M L C$ versus dimensionless moving speed $\bar{c}$ for various moving pulses

\section{Concluding remarks}

In cases of bottom slamming and bow flare slamming, the water impact load is a dynamic pressure which moves along the ship hull plates. In the process of obtaining the static equivalent design pressure, two effects need to be considered: the dynamic nature of the pressure and the moving nature of the slamming pressure. In this study, analytical solutions of the dynamic response of clamped rectangular plates under spatially uniform distributed impact loads and moving impact loads are derived by use of a modal superposition method in combination with the Lagrange equation. The moving impact load is simplified as three typical pulse loads: a rectangular pulse, a linearly decaying pulse and an exponentially decaying pulse, which travel along the plate.

The moving or propagating speed $c_{x}$ of a slamming impact load depends on the water entering velocity $V$ and deadrise angle $\beta$ of the wedge shaped forebody, see Eq. (1). The results show that the maximum plate deflection for slowly moving speeds is smaller than the static counterpart. However, when the moving speed exceeds the characteristic speed of the plate a significant increase of the maximum deflection of the elastic plate is observed.

For the considered typical $12 \mathrm{~mm}$ plate field and a deadrise angle $\beta$ equal to $10^{\circ}$ the moving speed equals the characteristic speed for an entering velocity equal to $6.0 \mathrm{~m} / \mathrm{s}$ and the 
dimensionless moving speed increases monotonically as the immersion speed increases.

Some of the results of the present analyses can be summarized as follows:

(1) For a rectangular pulse, the ratio between the maximum dynamic deflection under the moving pulse load and the deflection under a static pressure with the same load amplitude, $D L F m$, increases with the increase of the moving speed, and is always smaller than the ratio between the dynamic plate deflection under a uniformly spatially distributed pulse load and the deflection under a static pressure with the same load amplitude, $D L F d$.

(2) The dynamic load factor $D L F m$ of the fully clamped rectangular plates under the three types of moving pressure pulses shows differences. For the same load impulse, the DLFm under the moving rectangular pulse is the largest, while the response for the moving exponentially decaying pulse is the smallest.

(3) The Dynamic Moving Load Coefficient $(D M L C)$, defined as the ratio between $D L F m$ and $D L F d$ to reflect the effect of the moving load, is provided as a function of dimensionless moving speed for the considered three types of moving pulses.

To apply the results, the load amplitude and the moving speed of the slamming load must be known. The non-dimensional moving speed can then be calculated based on the plate dimensions. An equivalent static pressure, $P_{s}$, can be found by multiplying with the dynamic load factor $D L F m$. Alternatively, the magnitude of an equivalent uniformly spatially distributed pulse load can be found by multiplying with the Dynamic Moving Load Coefficient $D M L C$.

For simplicity the paper only present results for linear- elastic, clamped, isotropic plate fields. However, it is quite straight forward to use the same analysis procedure for analysis of plane orthogonally stiffened panel segments.

\section{Acknowledgments}

The authors would like to thank the support of Wuhan University of Technology for the research fund for Distinguished Professors (WUT: 471-40120163) and the project of National Natural Science Foundation of China (Grant No. 51809205). 

470 and $\nabla^{2}=\frac{\partial^{2}}{\partial x^{2}}+\frac{\partial^{2}}{\partial y^{2}}$ is Laplacian operator.

471

\section{Appendix A. Solution of the modal shape} other.

denoting that

where $\gamma$ is the coefficient of frequency.

The fixed-end boundary conditions are

where $n$ is the normal direction.

The governing equation of the free vibration of the plate surrounded by fluid from one side is

$$
D \nabla^{4} Z(x, y, t)+m^{\prime} \frac{\partial^{2} Z(x, y, t)}{\partial t^{2}}=0
$$

where $D=\frac{E h^{3}}{12\left(1-v^{2}\right)}$ is the bending rigidity of the plate, and $\nabla^{4}=\nabla^{2} \nabla^{2}$ is the bi-harmonic operator,

The solution of Eq. (A1) is the sum of the vibrations of all the modes independent of each

$$
Z(x, y, t)=[A \cos (\omega t)+B \sin (\omega t)] W(x, y)
$$

where $W(x, y)$ is the mode shape function, and $\omega$ is the natural frequency. Using Eq. (A1) and Eq. (A2), the intrinsic differential equations can be obtained

$$
\nabla^{4} W-\omega^{2} \frac{m^{\prime}}{D} W=0
$$

$$
\omega^{2} \frac{m^{\prime}}{D}=\gamma^{4}
$$

$$
Z=0, \frac{\partial Z}{\partial n}=0
$$

and the Simply-Supported boundary conditions are

$$
Z=0, \frac{\partial^{2} Z}{\partial n^{2}}=0
$$

Considering the following vibration mode functions in the form of separate variables

$$
W(x, y)=\exp (\psi x) \times \exp (\lambda y)
$$

Substituting Eq. (A4) and Eq. (A7) in Eq. (A3), and it can be obtained

$$
\lambda^{4}+2 \lambda^{2} \psi^{2}+\psi^{4}=\gamma^{4}
$$

The spatial eigenvalue can be solved from Eq. (A8)

$$
\psi_{1,2}= \pm i \alpha_{1}, \psi_{3,4}= \pm \alpha_{2}
$$




$$
\lambda_{1,2}= \pm i \beta_{1}, \lambda_{3,4}= \pm \beta_{2}
$$

492 where

493

494

495

496

497

498

499

500

501

502

503

504

505

506

507

508

509

510

511

512 where

513 method.

$$
\alpha_{1}=\sqrt{\gamma^{2}+\lambda^{2}}, \alpha_{2}=\sqrt{\gamma^{2}-\lambda^{2}}
$$

The Eigen functions of the two directions are

$$
\beta_{1}=\sqrt{\gamma^{2}+\psi^{2}}, \beta_{2}=\sqrt{\gamma^{2}-\psi^{2}}
$$

For the fully clamped plate, the analytical solution in Ref. [44] is used. Homogeneous linear equations of $A_{1} \sim A_{4}$ about the four boundary conditions of the edge $x=0$ and $x=a$ are obtained, and the homogeneous linear equations of $B_{1} \sim B_{4}$ about the four boundary conditions of the edge $y=0$ and $y=b$ are obtained. Let the coefficient determinant of these two homogeneous linear equations be equal to zero, and two eigenvalue transcendental equations are obtained. The eigen-equations corresponding to the fully clamped boundary conditions of the rectangular plate are:

$$
\begin{aligned}
& \frac{1-\cos \left(\beta_{1} b\right) \cosh \left(\beta_{2} b\right)}{\sin \left(\beta_{1} b\right) \sinh \left(\beta_{2} b\right)}=\frac{\beta_{1}^{2}-\beta_{2}^{2}}{2 \beta_{1} \beta_{2}} \\
& \frac{1-\cos \left(\alpha_{1} a\right) \cosh \left(\alpha_{2} a\right)}{\sin \left(\alpha_{1} a\right) \sinh \left(\alpha_{2} a\right)}=\frac{\alpha_{1}^{2}-\alpha_{2}^{2}}{2 \alpha_{1} \alpha_{2}}
\end{aligned}
$$

The three nonlinear equations (A8, A15, A16) are iteratively solved by the Newton-Raphson

Finally, analytical solutions of vibration mode functions and natural frequencies can be obtained.

$$
W(x, y)=X(x) Y(y)=\left[-\cos \left(\alpha_{1} x\right)+\frac{\alpha_{2}}{\alpha_{1}} k_{2} \sin \left(\alpha_{1} x\right)+\cosh \left(\alpha_{2} x\right)-k_{2} \sinh \left(\alpha_{2} x\right)\right]
$$

$$
\times\left[-\cos \left(\beta_{1} y\right)+\frac{\beta_{2}}{\beta_{1}} k_{1} \sin \left(\beta_{1} y\right)+\cosh \left(\beta_{2} y\right)-k_{1} \sinh \left(\beta_{2} y\right)\right]
$$

$$
\omega=\frac{D}{m^{\prime}}\left(\alpha_{2}^{2}+\beta_{2}{ }^{2}\right)
$$

$$
k_{1}=\frac{\cos \left(\beta_{1} b\right)-\cosh \left(\beta_{2} b\right)}{\left(\beta_{2} / \beta_{1}\right) \sin \left(\beta_{1} b\right)-\sinh \left(\beta_{2} b\right)}
$$




$$
k_{2}=\frac{\cos \left(\alpha_{1} a\right)-\cosh \left(\alpha_{2} a\right)}{\left(\alpha_{2} / \alpha_{1}\right) \sin \left(\alpha_{1} a\right)-\sinh \left(\alpha_{2} a\right)}
$$

Appendix B. Solution of the dynamic response of a plate under moving rectangular pulse

517 Substituting Eq. (17) into Eq. (11), the following expression can be obtained

$$
f(x, y, t) P_{1}(x, y)=g(x, y, t)=\int_{0}^{a} \int_{0}^{b} P(x, y, t) W_{i j}(x, y) d x d y
$$

519 The modal deflections can be determined from Eq. (12b):

$$
\ddot{A}_{i j}+\omega_{i j}{ }^{2} A_{i j}=\frac{g(x, y, t)}{m^{\prime} \int_{0}^{a} \int_{0}^{b} W_{i j}{ }^{2}(x, y) d x d y}
$$

When $l_{d}<a, l_{d}$ is defined as the product of the moving speed of the load and the load duration, i.e. $l_{d}=c_{x} t_{d}$, we have:

$$
g(x, y, t)=\left\{\begin{array}{lr}
p_{m} \int_{0}^{b} Y(y) d y \int_{0}^{c_{x} t} X(x) d x, & 0<t \leq t_{d} \\
p_{m} \int_{0}^{b} Y(y) d y \int_{c t-l_{d}}^{c_{x} t} X(x) d x, & t_{d}<t \leq \frac{a}{c_{x}} \\
p_{m} \int_{0}^{b} Y(y) d y \int_{c t-l_{d}}^{a} X(x) d x, & \frac{a}{c_{x}}<t \leq \frac{l_{d}+a}{c_{x}} \\
0, & \frac{l_{d}+a}{c_{x}}<t
\end{array}\right.
$$

524 where $X(x)$ and $Y(y)$ are the eigen functions in the $x$ direction and $y$ direction, respectively, see Appendix A.

When $l_{d} \geq a$, the following expression can be obtained

$$
g(x, y, t)=\left\{\begin{array}{lc}
p_{m} \int_{0}^{b} Y(y) d y \int_{0}^{c_{x} t} X(x) d x, & 0<t \leq \frac{a}{c_{x}} \\
p_{m} \int_{0}^{b} Y(y) d y \int_{0}^{a} X(x) d x, & \frac{a}{c_{x}}<t \leq t_{d} \\
p_{m} \int_{0}^{b} Y(y) d y \int_{c_{x} t-l_{d}}^{a} X(x) d x, & t_{d}<t \leq \frac{l_{d}+a}{c_{x}} \\
0, & \frac{l_{d}+a}{c_{x}}<t
\end{array}\right.
$$

528 Based on Eq. (12a), we have

$$
P_{1}(x, y)=p_{m} \int_{0}^{b} Y(y) d y
$$

530 Then, the time varying part of $f(x, y, t)$ for $l_{d}<a$ has the following form 


$$
f(x, y, t)=\left\{\begin{array}{lr}
\int_{0}^{c_{x} t} X(x) d x, & 0<t \leq t_{d} \\
\int_{c t-l_{d}}^{c_{x} t} X(x) d x, & t_{d}<t \leq \frac{a}{c_{x}} \\
\int_{c t-l_{d}}^{a} X(x) d x, & \frac{a}{c_{x}}<t \leq \frac{l_{d}+a}{c_{x}} \\
0, & \frac{l_{d}+a}{c_{x}}<t
\end{array}\right.
$$

532 When $l_{d} \geq a$, the following expression can be obtained

$$
f(x, y, t)=\left\{\begin{array}{lr}
\int_{0}^{c_{x} t} X(x) d x, & 0<t \leq \frac{a}{c_{x}} \\
\int_{0}^{a} X(x) d x, & \frac{a}{c_{x}}<t \leq t_{d} \\
\int_{c_{x} t-l_{d}}^{a} X(x) d x, t_{d}<t \leq \frac{l_{d}+a}{c_{x}} \\
0, & \frac{l_{d}+a}{c_{x}}<t
\end{array}\right.
$$

534 Then, the time independent term can be obtained:

535

$$
A^{*}{ }_{i j}=\frac{p_{m} \int_{0}^{b} Y(y) d y}{\omega_{i j}^{2} m^{\prime} \int_{0}^{a} \int_{0}^{b} W_{i j}{ }^{2}(x, y) d x d y}
$$

536 and the dynamic time varying load factor for the moving rectangular pulse is:

$$
(D L F)_{i j}=\sum D L F_{i j t}
$$

538 where $D L F_{i j t}$ can be derived as:

$$
\begin{aligned}
D L F_{i j t}= & \left\{\begin{array}{lr}
\omega_{i j} \int_{0}^{t} \int_{0}^{c_{x} \tau} X(x) d x \sin \omega_{i j}(t-\tau) d \tau, & 0<t \leq t_{d} \\
\omega_{i j} \int_{0}^{t} \int_{c_{x} \tau-l_{d}}^{c_{x} \tau} X(x) d x \sin \omega_{i j}(t-\tau) d \tau, & t_{d}<t \leq \frac{a}{c_{x}} \\
\omega_{i j} \int_{0}^{t} \int_{c_{x} \tau-l_{d}}^{a} X(x) d x \sin \omega_{i j}(t-\tau) d \tau, & \frac{a}{c_{x}}<t \leq \frac{l_{d}+a}{c_{x}}, l_{d} \leq a \\
0, & \frac{l_{d}+a}{c_{x}}<t
\end{array}\right. \\
D L F_{i j t}= & \begin{array}{ll}
\omega_{i j} \int_{0}^{t} \int_{0}^{c_{x} \tau} X(x) d x \sin \omega_{i j}(t-\tau) d \tau, & 0<t \leq \frac{a}{c_{x}} \\
\omega_{i j} \int_{0}^{t} \int_{0}^{a} X(x) d x \sin \omega_{i j}(t-\tau) d \tau, & \frac{a}{c_{x}}<t \leq t_{d} \\
\omega_{i j} \int_{0}^{t} \int_{c_{x} \tau-l_{d}}^{a} X(x) d x \sin \omega_{i j}(t-\tau) d \tau, t_{d}<t \leq \frac{l_{d}+a}{c_{x}} \\
0, & \frac{l_{d}+a}{c_{x}}<t
\end{array}
\end{aligned}
$$

By substituting Eqs. (B8-B11) into Eq. (16), the deflection of the plate can be obtained. 


\section{References}

544 [1] Zhu L. Development of requirements to safeguard large container ships from the effects of bow flare slamming.

545 Lloyd's Register Technical Association. 2007.

546 [2] Von Karman. The impact on seaplane floats during landing. Technical report 321. NACA; 1929.

547 [3] Wagner H. Uber stoss und gleitvorgänge an der oberfläche von flüssigkeiten. ZAMM 1932;12:193-215.

548 [4] Watanabe I. Analytical expression of hydrodynamic impact pressure by matched asymptotic expansion technique.

549 The Western shipbuilding Association. 1986:77-85.

550 [5] Faltinsen, OM (2000). Hydroelastic slamming. Journal of Marine Science and Technology, 5(2), 49-65.

551 [6] Wilson SK. A mathematical model for the initial stages of fluid impact in the presence of a cushioning fluid 552 layer. Journal of Engineering Mathematics. 1991;25:265-85.

553 [7] Bao CM, Wu GX, Xu G. Simulation of freefall water entry of a finite wedge with flow detachment. Applied 554 Ocean Research. 2017;65:262-78.

555 [8] Wu GX, Sun SL. Similarity solution for oblique water entry of an expanding paraboloid. Journal of Fluid 556 Mechanics. 2014;745:398-408.

557 [9] Seng S. Slamming and whipping analysis of ships. PhD Thesis, Technical University of Denmark, Mechanical 558 Engineering. 2012.

559 [10] Wang S, Guedes Soares C. Hydroelastic analysis of a rectangular plate subjected to slamming loads. Journal of 560 Marine Science and Application. 2017; 16(1):1-12.

561 [11] Ochi MK. Extreme Behaviour of a Ship in Rough Seas - Slamming and Shipping of Green Water, SNAME 562 Transactions. 1964.

563 [12] Ochi MK. Prediction of occurence and severity of ship slamming at sea. Fifth Symp. on Naval Hydrodynamics. 564 1964. 545-96.

565 [13] Ochi MK. A method to estimate slamming characteristics for ship design. Marine Technology. 1971. $219-232$.

566 [14] Ochi MK, Motter LE. Prediction of slamming characteristics and hull response for ship design. Transactions 567 Sname. 1973.

568 [15] Zhu L, Faulkner D. Design pressure for the wet-deck structure of twin-hull ships. Swath Ships. 2nd conference 569 on Fast Sea Transportation. 1995. Travemunde.

570 [16] Chuang SL. Experiments on slamming of wedge-shaped bodies. Journal of Ship Research. 1967;11:190-8. 
571 [17] Zhu L, Guo K, Duan L, Liu J, Wang H, Wang X. Wet-deck slamming pressure on SWATH-consideration for 572 practical design. 13th International Symposium on Practical Design of Ships and Other Floating Structures . 2016. 573 Copenhagen.

574 [18] Engle A, Lewis R . A comparison of hydrodynamic impacts prediction methods with two dimensional drop 575 test data. Marine Structures. 2003; 16(2):175-182.

576 [19] Luo H, Wang H, Soares CG. Numerical and experimental study of hydrodynamic impact and elastic response 577 of one free-drop wedge with stiffened panels. Ocean Engineering. 2012; 40(1):1-14.

578 [20] Panciroli R, Porfiri M. Evaluation of the pressure field on a rigid body entering a quiescent fluid through 579 particle image velocimetry[J]. Experiments in Fluids, 2013, 54(12).

580 [21] Zhao R, Faltinsen OM. Water entry of two-dimensional bodies. Journal of Fluid Mechanics. 1993; 246: 593581612.

582 [22] Payne PR. The Vertical Impact of a Wedge on a Fluid. Ocean Engineering. 1981; 8(4): 421-436.

583 [23] Jones N. Slamming damage. Journal of Ship Research. 1973;17:80-6.

584 [24] Paik JK, Lee JM, Shin YS, Wang G. Design principles and criteria for ship structures under impact pressure 585 loads arising from sloshing, slamming and green seas. Transactions - Society of Naval Architects and Marine 586 Engineers. 2004;112:292-313.

587 [25] Okada S, Sumi Y. On the water impact and elastic response of a flat plate at small impact angles. Journal of 588 marine science and technology. 2000; 5(1): 31-39.

589 [26] Yettou E-M, Desrochers A, Champoux Y. Experimental study on the water impact of a symmetrical wedge. 590 Fluid Dynamics Research. 2006; 38(1): 47.

591 [27] Lv J, Grenestedt JL. Some analytical results for the initial phase of bottom slamming. Marine Structures. $592 \quad 2013 ; 34: 88-104$.

593 [28] Lv J, Grenestedt JL. Analytical study of the responses of bottom panels to slamming loads. Ocean Engineering. $594 \quad 2015 ; 94: 116-25$

595 [29] Datta N, Siddiqui MA. Dynamic response of axially loaded plates with intermediate fixities to transient 596 hydrodynamic impact loads. 32nd International Conference on Ocean, Offshore and Arctic Engineering. 2013. 597 Nantes.

598 [30] Datta N, Siddiqui MA. Hydroelastic analysis of axially loaded Timoshenko beams with intermediate end 599 fixities under hydrodynamic slamming loads. Ocean Engineering. 2016;127:124-34.

600 [34] Zhu L, Duan L, Yu TX, Guedes Soares C. Dynamic elasto-plastic response of ship plates subjected to slamming 
602 [32] Friba L. Vibration of solids and structures under moving loads. New York: Thomas Telford; 1999. p. $247-251$.

603 [33] Alisjahbana SW. Dynamic response of clamped orthotropic plates to dynamic moving loads. 13th World 604 Conference on Earthquake Engineering. 2004. Vancouver, B.C.

605 [34] ABS. Rules for building and classing steel vessels. Pt. 5c Ch.1 Sec.6; 2018. p. 147-149.

606 [35] CCS. Guidelines of small waterplane area twin hull craft. 2005. p. 19-25.

607 [36] Lloyd's Register (LR). Rules and regulations for the classification of ships. Pt.4 Ch.8 Sec.12; 2017. p. $782-783$.

608 [37] American Bureau of Shipping (ABS). Guide for slamming loads and strength assessment for vessels. Sec.8; 609 2016. p. 24.

610 [38] Zhu L, Bai XY, Yu TX. The saturated impulse of fully clamped square plates subjected to linearly decaying 611 pressure pulse. International Journal of Impact Engineering. 2017; 110: 198-207.

612 [39] Zhu L, He X, Chen FL, Bai XY. Effects of the strain rate sensitivity and strain hardening on the saturated 613 impulse of plates. Latin American Journal of Solid and Structures. 2017:14(7): 1273-1292.

614 [40] Bai XY, Zhu L, Yu TX. Saturated impulse for fully clamped square plates under blast loading. International 615 Journal of Mechanical Sciences. 2018;146-147:417-431.

616 [41] Faltinsen OM. Hydrodynamics of high-speed marine vehicles. Cambridge University Press; 2005.

617 [42] Alexandr I. Korotkin. Added masses of ship structures. Springer Science; 2008. p. 261-264.

618 [43] Biggs, John M. Introduction to structural dynamics. McGraw-Hill College; 1964. p. 158-160.

619 [44] Xing Y, Liu B. Exact solution of free vibrations of plates and shells. Beijing: China Science Press; 2015. p. 962011.

\section{Notation}

$\begin{array}{ll}A & \text { modal amplitude } \\ A_{i j s t} & \text { modal static deflection of the plate } \\ a & \text { length of the rectangular plate } \\ b & \text { breadth of the rectangular plate } \\ c_{x} & \text { moving speed of the impact load } \\ c_{0} & \text { natural velocity, velocity of the load moving from one side to another side of the plate during a natural } \\ & \text { period, } c_{0}=a / T \\ \bar{c} & \text { dimensionless moving speed, } c_{x} / c_{0}\end{array}$




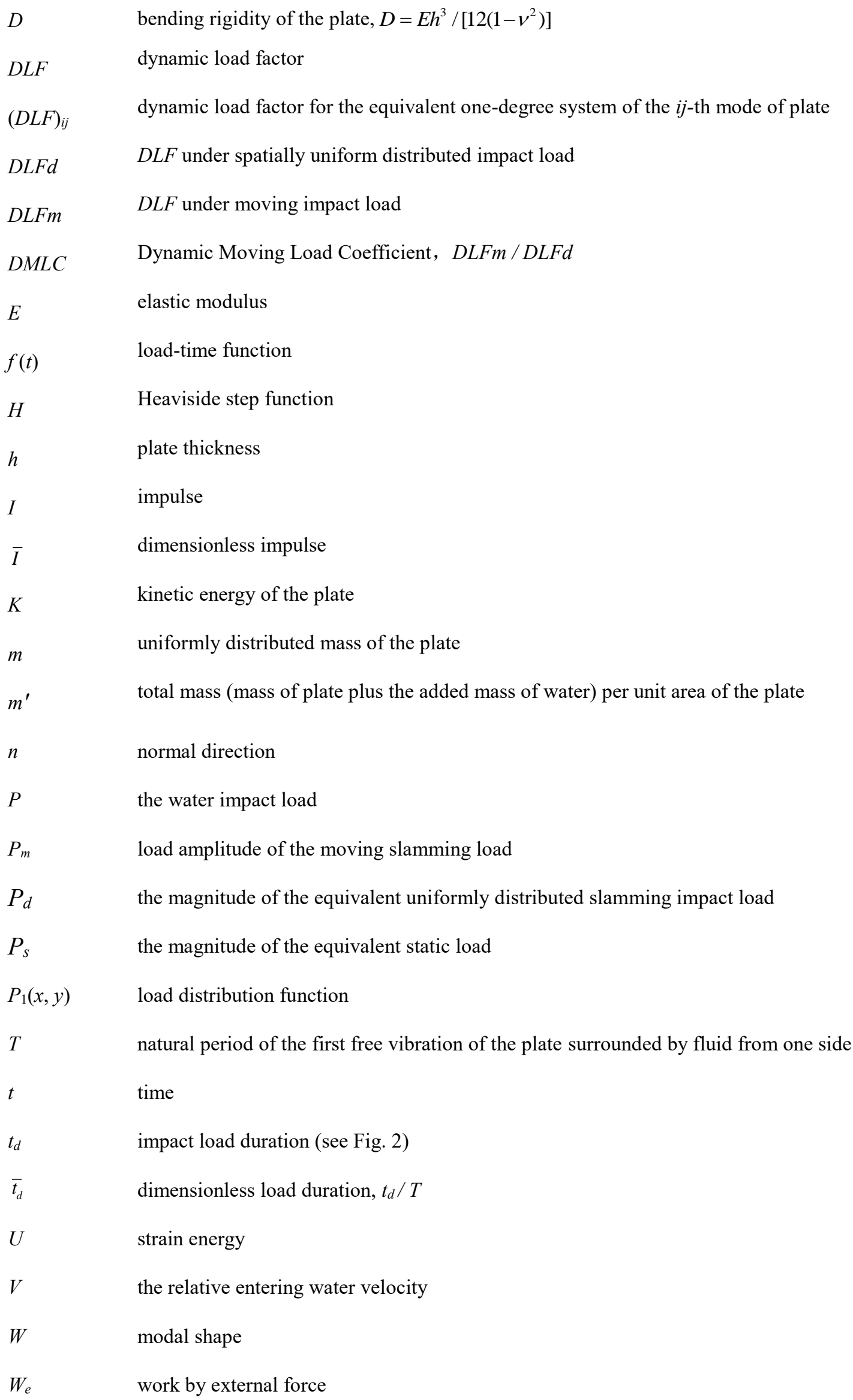




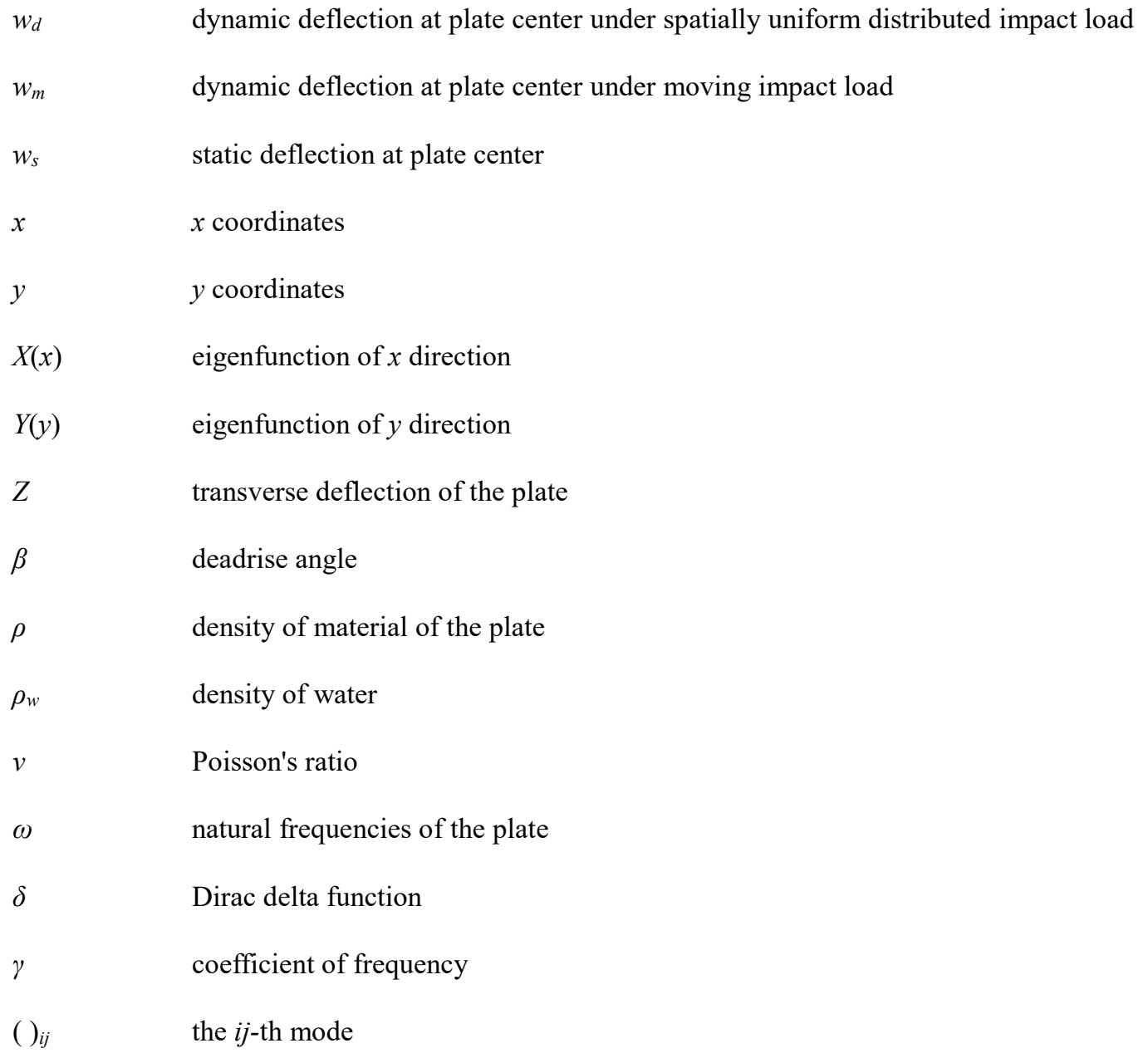

